\title{
José Luis García Guerrero y María Luz Martínez Alarcón (dirs.). Constitucionalizando la globalización, Editorial Tirant lo Blanch, Valencia, 2019, 2 Volúmenes, 1700 pp., ISBN
}

http://dx.doi.org/10.18543/ed-67(2)-2019pp419-423

\section{I}

La globalización, en sus múltiples vertientes, pero muy especialmente en sus aspectos jurídicos, económicos y sociales, ha supuesto un revulsivo jurídico-constitucional al concepto racional-normativo del constitucionalismo histórico, centrado en las esferas políticas nacionales $\mathrm{y}$, en el ámbito europeo, en su contexto multinivel.

Este fenómeno ha modulado la interlocución clásica de los ciudadanos y los poderes públicos, ampliando las esferas de interacción, gracias a la dilución de las fronteras nacionales, la integración económica y la rápida extensión de las libertades de circulación de personas y mercancías.

Indudablemente, todo este proceso lleva anejo una serie de problemáticas que, tanto desde la perspectiva de la legitimidad democrática, -especialmente en lo relativo a la toma de decisiones de las instituciones europeas y mundiales-, como en lo relativo a los derechos fundamentales de los ciudadanos, -la limitación de los mismos, como se puso de manifiesto con la larga crisis económica-, afectan al núcleo esencial del Estado Social y Democrático de Derecho.

La globalización es, por lo tanto, un complejo proceso que, como tal, posee incidencia plural, por lo que sus implicaciones, causas y consecuencias deben ser analizadas con perspectiva holística. Tanto es así que su complejidad acaba produciendo la mutación de la globalización conforme las propias trasformaciones de la misma se manifiestan, exigiendo afrontar nuevos desafíos, porque la naturaleza intrínseca de la globalización es su dinamismo catalizador en todos los ámbitos en los que se desenvuelve como realidad socioeconómica.

\section{II}

La obra, coordinada por los profesores José Luis García Guerrero y María Luz Martínez Alarcón, de la Universidad de Castilla-La Mancha, es una amplia y densa obra coral en dos volúmenes que destila un intenso y sesudo trabajo de investigación multifocal pero con un común denominador: la determinante influencia de la globalización y sus aspectos económicos en el constitucionalismo contemporáneo. 
Una perspectiva novedosa, no suficientemente abordada, pero que en esta obra, llamada a convertirse en un estudio canónico sobre el tema, los autores afrontan desde la convicción de la irreversibilidad de la globalización y la necesidad de su conocimiento profundo.

El trabajo, compuesto de veintinueve capítulos agrupados en seis partes, presenta un detallado análisis orgánico e institucional no exento de las vertientes crítica y propositiva, al objeto de propiciar un debate sobre las cuestiones planteadas. Por lo tanto, lejos de ser un estudio meramente descriptivo, exento de opinión, centra el problema y su debate.

En relación con la primera parte, relativa a los Tipos de integración económica, examina las derivadas de los acuerdos de libre comercio, -por María Mercedes Sanz Gómez-, la unión aduanera, -por Pilar Molero-, la teoría del mercado común, -por Magdalena González-, la unión económica supraestatal, -por Ignacio García Vitoria-, y la unidad económica y monetaria, -por Pablo Meix-.

En este parte, los autores presentan, a modo de caleidoscopio, el panóptico general de la llamada globalización económica, y cómo el mercado común, la supresión de barreras al libre comercio y, en definitiva, la unión económica y monetaria, han transformado la forma de ver, entender y plantear las relaciones económicas internacionales, articulando una nueva realidad sociopolítica presidida por el comercio, de alcance superior conforme se va diluyendo el tradicional criterio fronterizo.

La segunda parte, titulada Estudio de la primera fase de las integraciones económicas, pone el foco en el aspecto histórico de dicha integración en sus varias fases, a partir de los ejemplos de la Comunidad Andina de Naciones, -elaborado por Ernani Contipelli-, NAFTA, - por Asier Tapia-, el Tratado de Libre Comercio de Centroamérica, -por María Martín-, MERCOSUR, -analizado por Federico E. Z. Glitz-, el Acuerdo Transpacífico de Cooperación Económica, -estudiado por Claudio di Maio-, el Foro de Cooperación Económica Asia-Pacífico y la Asociación de Naciones del Sudeste Asiático, -por Ernani Contipelli y Simona Picciau-, la Alianza del Pacífico, -por Jairo Castaño-, o, por último, los casos del Acuerdo Integral sobre economía y comercio, -planteado por Jorge Luis Fabra-, la Asociación Económica Integral Regional, -por Héctor Álvarez-, o la Asociación Transatlántica para el Comercio y la Inversión, -realizado por Ángel Aday Jiménez-. Toda esta parte se completa con un muy útil compendio de acuerdos comerciales por estado elaborado por Miguel Ángel Sevilla y José Luis García Guerrero.

Una parte especialmente interesante, no ya para el público en general, sino para el académico en particular, toda vez que, más allá de determinadas organizaciones económicas internacionales, la inmensa mayoría de las estudiadas resultan desconocidas. Con ello, se comprende mejor el planteamiento abordado por muchos países en el ámbito de la integración económica regional, y por lo tanto, las implicaciones en lo relativo a las relaciones internacionales, en donde el tradicional eje de influencia geoestratégico viene presidido, hoy, por la economía y el comercio, y no por criterios militares. 
La tercera parte, dedicada a los $M o$ delos de Constitución Económica, constituye en mi opinión la parte más sugerente del libro, al abordar un complejo enormemente rico desde el panorama jurídico, que parte del estudio del carácter racional-normativo de la constitución económica liberal, -por Jesús López de Lerma-, la constitución económica marxista-leninista, -analizada por Lissette Pérez-, el intervencionismo del Estado Social, -realizado por Mercedes Serrano-, y la fundamental perspectiva europea, con los estudios de la economía social de mercado, -por Gabriel Moreno-, y el llamado ordoliberalismo, -estudiado por Luis Ignacio Gordillo-- Concluye este trascendental enfoque con el trabajo sobre la desconstitucionalización de la Constitución Económica Española que afronta José Luis García Guerrero.

La combinación de estudios críticos desde la óptica normativa y filosófico-teórica que se plasma en esta parte es de un extraordinario interés conceptual, al unir los ámbitos de la economía política, la historia y los modelos constitucionales económicos europeos. El examen de conjunto permite inferir un alto grado de conexión entre todas las materias, contribuyendo a apreciar los matices, diferencias y semejanzas entre modelos, pero también su posibilismo, su virtualidad real y, desde la conjunción de los planteamientos históricos y jurídicoeconómicos, un balance crítico de su implantación en determinados países. El resultado, un panorama horizontal de los modelos económicos vigentes, con sus debilidades y fortalezas, y su grado de efectividad desde el constitucionalismo moderno.
La cuarta parte, la más extensa de toda la obra, titulada El gobierno interno de la globalización: los bancos centrales. Su rol en el libre comercio, expone la visión orgánico-institucional del constitucionalismo económico, sus modelos de gobernanza y su estructura operativa y funcional. Así, se comienza con los estudios sobre los bancos centrales en Japón, China e India, -elaborada por Eduardo Sanz-, continuando con los relativos a Brasil, Canadá y Rusia, - por Marcelo Teixeira-, y la FED en los Estados Unidos, -realizado por Tomás Bastarreche-, sin olvidar, en el ámbito de la Unión Europea, a nuestro referente europeo, el Banco Central Europeo, -que aborda Isabel Giménez-, el interesante análisis comparativo entre los bancos centrales de Alemania, España, Francia e Italia, -por Elena Rebato-, o el Banco de Inglaterra, -que estudia Tomás Bastarreche-, sin olvidar al Banco Internacional de Pagos, -por Tomás Bastarreche y Eduardo Sanz-.

Se completa esta parte con los sugestivos trabajos que, sobre el gobierno externo o la gobernanza internacional de la globalización se realiza desde el análisis de los vínculos entre la Unión Europea y la Organización Mundial de Comercio, -por Naiara Arriola-, el G-20, -que estudia Enrique Belda-, la OCDE, -que aborda Juan Manuel Goig-, o, en último lugar, los casos del Fondo Monetario Internacional, -por Tomás Vidal-, o el Banco Mundial, -que expone Ana Valero-.

Una parte, en conjunto, muy sugerente, que ayuda a conocer a fondo, interna y externamente, las estructuras técnicas de poder en la toma de 
decisiones económicas de la globalización, cuya implicación en las políticas públicas requiere entender las estructuras de la gobernanza económica mundial en sus aspectos más complejos, que a la postre, suelen ser los más determinantes política y económicamente. Una suerte de arcanos institucionales que, en el siglo XXI, ordenan las relaciones económicas internacionales.

Una quinta parte, denominada $\mathrm{Al}$ gunos problemas que plantea la globalización, sirve de colofón a esta extensa e intensa obra. Un estudio que no podía faltar en un trabajo de este calado sobre la transformación del constitucionalismo moderno por la influencia de la globalización.

En ella, se acomete el análisis de los embates de la globalización a la democracia, -por José Luis García Guerrero-, la afectación de la integración económica y la globalización a los valores y al Estado Social, -que estudia Luis Jimena-, el coste económico de los derechos y su interpretación, -que afronta Francisco Javier Díaz Revorio-, las implicaciones para los derechos de los trabajadores, -por Carlos Vidal Prado-, la configuración constitucional de los tributos en la globalización, -que expone Juan José Nieto-, o la difícil conexión entre integración económica y medio ambiente, -que presentan Silvana Winckler, Arlene Renk y Reginaldo Pereira-.

Esta parte, crítica y analítica, no obvia los polémicos debates que entraña la globalización para la sociedad, los derechos fundamentales, los deberes constitucionales y el medio ambiente, y que, en el fondo, están determinando la orientación de la misma globalización a través de sus deficiencias, no siempre resueltas y que, en la actualidad, son las más contestadas social y políticamente.

Una sexta y última parte, titulada, ¿Puede la Unión Europea solventar estos problemas de la globalización reformando sus instituciones o precisa transformarse en un Estado federal?, muestra las ponencias de Antonio López Castillo y Mattias Kumm en torno a una mesa redonda moderada por Juan José Solozábal, en la que se sugirieron y propusieron relevantes cuestiones sobre la arquitectura institucional de la globalización pre y post crisis. Una crisis cuya duración y virulencia han servido para cuestionar las costuras políticas, económicas y sociales de la globalización.

En definitiva, una magna obra, integral en cuanto a su fundamentación, objetivos y alcance, que va a servir de soporte intelectual para la comprensión del fenómeno de la globalización, su arquitectura jurídico-institucional, su conexión con la geoestrategia y las relaciones internacionales y, por supuesto, en lo relativo a los derechos económicos y sociales, cuya naturaleza y límites se ven modulados por un escenario político-económico en el que, en no pocas ocasiones, el ciudadano, como actor individual, ve soslayados sus derechos e intereses en pro de un interés global de cuestionable aplicación práctica.

\section{III}

La globalización ha modulado la perspectiva económica de la realidad político-constitucional, transformando la concepción tradicional del constitucionalismo para otorgarle una nueva voz que incide de forma 
determinante, $-\mathrm{y}$ sin vuelta atrás-, en la interpretación y aplicación de los textos constitucionales.

Este nuevo panorama, que podría ser definido como una suerte de complejo orgánico constitucional por la profunda imbricación de sus redes y por la vertiente institucional que le otorga contenido normativo y un alto grado de eficacia económica, ha estado tradicionalmente soslayado de los estudios críticos constitucionales, que lo han desdeñado como un actor carente de relevancia jurídico-constitucional.

El tiempo y la aplicabilidad directa, en sus vertientes orgánica y funcional, de este nuevo constitucionalismo económico, ha acabado por alejar estos carpetovetónicos planteamientos, que desconocían la sólida y estable conexión de los caracteres sustantivos de los conceptos de economía y constitución.

Sus implicaciones en el conjunto de los derechos fundamentales, -no sólo los derechos sociales-, y la legitimidad democrática, exigen de un estudio riguroso, extenso e intenso, del nuevo marco jurídico de la globalización y su incidencia en el constitucionalismo moderno.

El panorama, en el ámbito de los derechos fundamentales, es de enorme trascendencia, no sólo porque no tiene vuelta atrás sino, aún más relevante, porque la orientación de los mismos acaba por ser determinada por actores supranacionales que carecen, en algunas ocasiones, de la necesaria legitimidad democrática.

Algo similar se predica de los organismos supranacionales que, financiados por los Estados, establecen un rumbo político-económico en el que los Estados más débiles ven limitada su actuación, debiendo acatar dicha orientación sin poder participar en la toma de decisiones.

En conclusión, la globalización es un presente armado de futuro, pero un presente y un futuro que exige de mecanismos constitucionales de ordenación que, desde la guía del Estado de Derecho y la protección de los derechos fundamentales, hagan de la integración económica mundial un fenómeno de progreso y prosperidad para todos.

\section{David Delgado Ramos \\ Profesor ayudante doctor de Derecho Constitucional \\ Universidad Rey Juan Carlos}




\section{José Luis García Guerrero y María Luz Martínez Alarcón (dirs.). Constitucionalizando la globalización, Editorial Tirant lo Blanch, Valencia, 2019, 2 Volúmenes, 1700 pp., ISBN}

http://dx.doi.org/10.18543/ed-67(2)-2019pp419-423

\section{Copyright}

Estudios de Deusto es una revista de acceso abierto, lo que significa que es de libre acceso en su in tegridad. Se permite su lectura, la búsqueda, descarga, distribución y reutilización legal en cualquier tipo de soporte sólo para fines no comerciales, sin la previa autorización del editor o el autor, siempre que la obra original sea debidamente citada y cualquier cambio en el original esté claramente indicado

Estudios de Deusto is an Open Access journal which means that it is free for full access, reading, search, download, distribution, and lawful reuse in any medium only for non-commercial purposes, without prior permission from the Publisher or the author; provided the original work is properly cited and any changes to the original are clearly indicated. 